\title{
Asian Spot Prices for LNG and Other Energy Commodities
}

\author{
Abdullahi Alim \\ The University of Western Australia
}

Peter R. Hartley, Ph.D.

George \& Cynthia Mitchell Professor of Economics, Rice University

Rice Faculty Scholar in Energy Studies, James A. Baker III Institute for Public Policy BHP Professor of Economics, The University of Western Australia

Yihui Lan, Ph.D.

Senior Lecturer

The University of Western Australia

(C) 2015 by the James A. Baker III Institute for Public Policy of Rice University This material may be quoted or reproduced without prior permission, provided appropriate credit is given to the author and the James A. Baker III Institute for Public Policy.

Wherever feasible, papers are reviewed by outside experts before they are released. However, the research and views expressed in this paper are those of the individual researcher(s) and do not necessarily represent the views of the James A. Baker III Institute for Public Policy. 


\begin{abstract}
We investigate the relationship between the Japan-Korea Marker (JKM) price of LNG, the price of Brent oil, and spot prices of fuel oil and thermal coal imported into Japan, South Korea, China, and Taiwan. We are especially interested in understanding the behavior of the JKM price and how it may reflect competition between fuels in Asia. The increasing proportion of spot and short-term trading of LNG, together with proposals to develop an LNG pricing hub in Asia with associated derivatives markets, have increased the interest in understanding how the JKM price behaves. It is also widely anticipated that imminent LNG exports from the US Gulf Coast to Asia and Europe will substantially disrupt historical pricing relationships between natural gas prices in different locations and the relationships between those prices and the price of oil. It therefore is of interest to characterize the behavior of LNG prices in Asia before these disruptions occur. Finally, our analysis has implications for the suitability of the JKM price as an alternative to oil or other spot natural gas prices for indexing long-term LNG contracts.
\end{abstract}

Keywords: Spot energy prices, LNG, Asia, inter-fuel competition, LNG contract trades, cointegration, vector error correction models

\title{
Introduction
}

In Asia as elsewhere in the world, increasing amounts of LNG are being traded under spot and short-term contracts. Data from the International Group of Liquefied Natural Gas Importers (GIIGNL) reveals that spot and short-term (defined by GIIGNL as contracts of less than four years duration) trading of LNG have grown from less than $19 \%$ of the total in 2010 to more than $29 \%$ in 2014 . For importers in Asia, the proportion of spot and short-term trading has more than doubled over the same period, from slightly below $13.4 \%$ in 2010 to almost $28.7 \%$ in 2014 . The most widely quoted measure of the prices of spot LNG trades in Asia is the Japan-Korea Marker (JKM) price published by Platts. It is based on prices reported in spot market trades and/or bids and offers collected after the close of the Asian trading day at 16:30 Singapore time. In this paper, we investigate the relationship between the JKM price, the price of Brent oil, and the prices of other competing energy commodities, specifically thermal coal and fuel oil.

The behavior of Asian energy prices, and the JKM price in particular, is of interest for a number of reasons. First, the large share of Asian countries in global energy demand suggests that they may have a large impact on world energy markets. According to the BP Statistical Review (2015), the Asia Pacific region accounted for 41.3\% of global primary energy consumption in 2014, which was almost double the share of Europe and Eurasia (21.9\%) or North America (21.8\%). Coal is the dominant fuel in the Asia Pacific region, supplying over $52 \%$ of primary energy consumption in 2014 . This compares to slightly below $26.8 \%$ for oil and slightly over $11.4 \%$ for natural gas.

Nevertheless, Asia-Pacific countries accounted for more than $72.8 \%$ of global imports of LNG. Despite the importance of Asian energy markets in general, and the Asian market for LNG in particular, research on Asian natural gas prices is scarce. 
Second, the growth in spot and short-term trading of LNG is likely to continue, making the behavior of spot prices particularly salient to market participants. Hartley (2015a), for example, argues that reducing risks, and hence the cost of finance, can explain why both LNG project developers and their customers like to have a substantial fraction of their export capacity or import requirements under long-term contract. He also shows, however, that there are advantages to retaining exposure to spot markets, and that spot market trades are likely to increase as spot markets for LNG become more liquid and better arbitraged.

Asian LNG exporters and importers exposed to spot markets need to understand how prices in those markets are likely to evolve relative to other energy commodity prices. In particular, since about half ${ }^{1}$ the imported LNG in northeast Asia is used to generate electricity, LNG prices will affect both short-term scheduling of existing generators and long-term investment in new generating capacity.

Traders, including so-called portfolio traders of branded ${ }^{2}$ LNG such as BG or Shell, are increasingly engaged in arbitraging LNG spot price differences over time and across locations. Singapore is building excess LNG storage capacity to encourage third parties to engage in LNG price arbitrage. Singapore has also expressed a desire to stimulate futures and options trading in LNG. Potential participants in such markets also have an interest in understanding the behavior of existing LNG spot prices.

Third, imminent LNG exports from the US Gulf Coast may substantially affect Asian LNG trading and the historical pricing relationships between natural gas prices in different locations. They could also affect the relationships between those prices and the price of oil. It therefore is of interest to characterize the behavior of LNG prices in Asia before these disruptions occur. The analysis can provide a benchmark to gauge the impacts of increasing US LNG exports.

The fourth reason for analyzing the relationship between the JKM and the oil price in particular is that the JKM price has been suggested as an alternative to oil as a reference price for long-term LNG contracts. As noted above, while the proportion of spot and short-term trading of LNG has been growing, there are also good reasons to expect long-term contracts to persist. Such contracts include indexation clauses that allow for price adjustments without the need to re-open negotiations. An oil price, such as the price of Brent, has been the most common reference price for indexation. Recently, however, natural gas spot prices such as the Henry Hub $(\mathrm{HH})$ price in the US, the National Balance Point (NBP) price in the UK, or the JKM have been suggested as alternatives.

\footnotetext{
${ }^{1}$ From International Energy Agency (IEA) energy balance statistics, the proportion of natural gas used for electricity generation is about $68 \%$ in Japan, $49 \%$ in Korea, $44 \%$ in Taiwan, and $19 \%$ in China. Using GIIGNL data on LNG imports, we deduce that about $50 \%$ of LNG imported by these countries would be used to generate electricity.

${ }^{2}$ These firms enter into contracts to sell LNG under their own name (hence the "branded" moniker) but are sourced from multiple liquefaction plants and transported in their own ships.
} 
The NBP is relevant to Asian LNG trades because the cost of shipping LNG from the Middle East to Europe or northeast Asia are similar, and spot cargoes can be sent in either direction in response to price differentials. LNG exports from the US will also be able to go to either Europe or Asia. The latter will also likely directly tie Asian prices more closely to the $\mathrm{HH}$ price, in part because trading agreements concluded by US LNG project developers differ radically from traditional bilateral long-term LNG contracts. Many developers are planning to operate their facilities under tolling arrangements. Customers will be responsible for buying natural gas from the US market at a price related to the HH price (typically 115\% of it), and for shipping the LNG.

The liquefaction plants will be paid a fee for turning the natural gas into LNG and loading the ships. To mitigate risks from volume fluctuations, plant owners have signed contracts that include take-or-pay clauses for use of a certain amount of their liquefaction capacity each year. The tolling arrangements thus require customers to bear many more risks associated with LNG trading, including risks associated with fluctuating US natural gas prices.

Figure 1 illustrates how much more variable $\mathrm{HH}$ prices have been relative to both the Brent oil price and the JKM price. Combining HH spot price data from the Energy Information Administration (EIA) with the data we shall use subsequently in this paper, we calculated series of rolling 28-day ${ }^{3}$ standard deviations $\sigma_{o i l}, \sigma_{H H}$ and $\sigma_{J K M}$ of the natural logarithms of the three prices over the period February 2, 2009-April 30, 2015. We then produced kernel density estimates (using epanechnikov functions with 150 points) of the resulting distributions of standard deviations.

\footnotetext{
${ }^{3}$ As a result of weekends and other non-trading days, the rolling windows contain fewer than 28 trading days even though the gap between the ending and beginning of each window is 28 days. Since most of the missing days are weekends, by choosing a window length a multiple of 7 , most windows will contain the same number of missing days. A window of 28 days is also consistent with the horizon used in the impulse response analysis presented later. Finally, as shown in Hartley (2015b), recent spot trades of LNG have traversed an average 6,000 nautical miles, which would take 13 days at 19 knots (a typical operating speed for an LNG carrier) or close to 28 days round-trip.
} 
Figure 1. Rolling 28-day standard deviations of log Brent, JKM, and HH prices

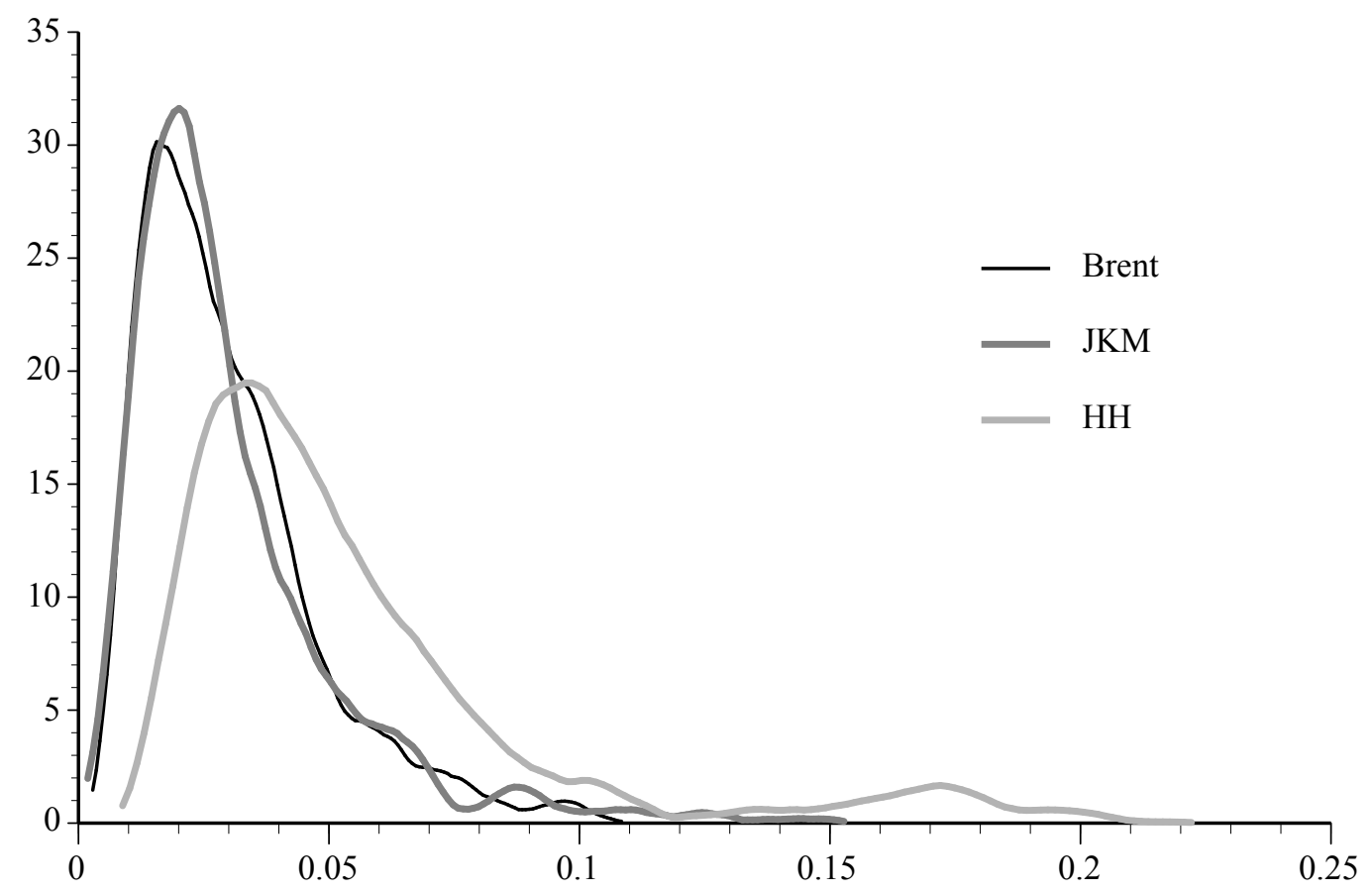

The mean of the log HH price 28 -day standard deviations is about $84 \%$ higher than the corresponding mean of the log Brent price standard deviations, while the median is about $72 \%$ higher. ${ }^{4}$ The maximum $\log \mathrm{HH}$ price standard deviation is more than double the maximum log Brent price standard deviation. By contrast, the distribution of standard deviations of the $\log$ JKM prices is much more similar to the distribution of $\log$ Brent price standard deviations. ${ }^{5}$ The mean is a little over $2 \%$ higher for JKM, but the median is about $3.4 \%$ lower. The JKM prices can experience periods of substantially higher volatility than the Brent prices, however, with the maximum log JKM price standard deviation being more than $42 \%$ higher than the maximum log Brent price standard deviation.

\footnotetext{
${ }^{4}$ Pindyck (2004) found the mean weekly standard deviation of the log of daily natural gas price changes in the US to be more than twice the mean weekly standard deviation of the log of daily oil price changes over the period May 2, 1990-February 26, 2003. Since he was measuring daily price changes, he corrected for the expectation that prices would be expected to change more when the elapsed time between observed prices is longer as from Fridays to the following Mondays or over holidays.

${ }^{5}$ The distributions of rolling 56-day standard deviations for the log JKM and log Brent prices are more distinct. The mean of the 56-day rolling standard deviations of the log JKM prices is about $22 \%$ higher than the corresponding mean of the 56 -day rolling standard deviations of the log Brent prices, and the median is about $24 \%$ higher. The relative variability of $\log \mathrm{HH}$ to $\log$ Brent prices, however, is more similar over the two horizons with the mean of the log $\mathrm{HH}$ prices being about $75 \%$ higher and the median about $72 \%$ higher (as in the 28 -day case).
} 
The higher volatility of the $\mathrm{HH}$ price relative to both the Brent oil price and the JKM price might suggest that Asian demand for LNG based on the $\mathrm{HH}$ price will be limited. This observation is reinforced by the results from the paper by Hartley and Medlock (2014), which will be discussed in more detail below. They concluded that, until US LNG exports commence, US shale gas development effectively made natural gas a nontraded good for the US. As a result, the foreign exchange value of the US dollar affected the relative price of oil to $\mathrm{HH}$. Since oil is internationally traded, its price in US dollars will tend to increase as the US dollar depreciates, and decrease as the dollar appreciates, relative to other currencies. On the other hand, the $\mathrm{HH}$ price was determined by domestic supply and demand and not directly affected by the exchange rate. This made the $\mathrm{HH}$ price look much lower relative to oil while the US dollar was weak. The low relative price of $\mathrm{HH}$, in turn, made purchases of LNG linked to the $\mathrm{HH}$ price more attractive. Once US natural gas becomes internationally traded, however, exchange rate movements will also affect the $\mathrm{HH}$ price and the latter will become more correlated with movements in the price of oil. In summary, we would expect a demand for LNG imports linked to the oil price, and to an Asian spot price such as JKM to persist even after US exports of LNG commence.

We turn next to a discussion of what we expect to find. In summary, different energy commodities are valued primarily ${ }^{6}$ for their energy content, which remains relatively stable. The relative prices of such commodities therefore also should be stable, implying that the log prices should be co-integrated.

Both demand and supply factors should limit movements in the relative prices of energy commodities. Different energy commodities are, or can be, substitutes in consumption for many uses. This does not require fuel-switching capability since capital using different fuels, but producing the same or substitute output, can be operated for different lengths of time. In the electricity industry, natural gas can be used in open-cycle gas turbines to serve peak load, or in combined-cycle gas turbines to serve intermediate or base load. Whether natural gas substitutes for, or complements, other fuels then depends on how it is used and the other types of generating plants that are available.

Supply side factors could also link natural gas and oil prices. If associated natural gas production is marketed rather than flared, higher oil prices and oil production could lead to higher natural gas production and lower natural gas prices. On the other hand, since re-injected natural gas is often used for secondary oil production, higher oil production might reduce the amount of marketed natural gas output. Perhaps most significantly, however, many resources used to produce natural gas can instead be used

\footnotetext{
${ }^{6}$ This is not strictly true for a number of reasons. The different types of capital that use each fuel as an energy source have different levels of energy efficiency. Differing energy densities in terms of energy per unit weight and energy per unit volume are particularly important for transport applications. Fuels that are liquid at normal temperatures and pressures are also much easier to transport and handle. Fuels also differ in the amounts of pollution they produce per unit of energy provided.
} 
to produce oil. Higher oil prices would attract these resources out of dry natural gas production and tend to reduce the supply of natural gas and raise its price.

Spot LNG prices in particular should be determined by temporary shifts in supply and demand for spot cargoes. On the supply side, liquefaction terminals usually contract up less than 100\% of their anticipated output to allow for plant outages (either planned or unplanned) and to take advantage of spot trading opportunities. Newly commissioned terminals may have even more output available for spot delivery if the owners were conservative about predicting construction times and delayed the start of long-term sales contracts. Some older terminals without the need to finance large capital investments may also leave more capacity available for spot trades after foundation long-term contracts expire.

Buyers may also make LNG available to the spot market when contracted flows are surplus to their needs. According to data from GIIGNL, re-exports of LNG have increased from slightly below 1 million tonnes in 2010 to more than 6.3 million tonnes in 2014. Recent weakness in the EU economy has stimulated the re-export of LNG from European ports. According to the BP Statistical Review (2015), Europe and Eurasia consumption of natural gas has declined every year since 2010 , with consumption in 2014 being lower than in any year since 2000 .

LNG that had been destined for the US market provided another source of spot LNG cargoes over the last five or so years. At the turn of the century, the US was expected to become the largest LNG importer in the world. According to EIA data, US monthly LNG imports increased from around $1.5 \%$ of US marketed natural gas production in 2002 to more than $3 \%$ in early 2003 , eventually peaking at slightly more than $6 \%$ in April 2007. With the extensive development of unconventional gas, however, US imports of LNG fell below $2 \%$ of marketed natural gas production from January 2011 and $1 \%$ from February 2012. Firms that had been preparing to export LNG to the US looked for other markets when US imports did not materialize.

On the demand side of the spot LNG market, unusual cold weather shocks can temporarily increase natural gas demand above long-term expected needs. Unusual hot weather can also raise natural gas consumption if increased air conditioning raises electricity demand. More generally, any factors that affect the demand for electricity can also alter natural gas demand.

Changes in relative fuel prices, or other factors affecting electricity production via other means (such as reduced hydroelectricity production in a drought), can also change the demand for natural gas. The Japanese earthquake and tsunami in March 2011 was one such event in the period under study. When the disaster caused radiation leaks from the Fukushima nuclear power plant, the Japanese government eventually shut down all of Japan's nuclear power plants. IEA data on energy flows in the Japanese electricity sector ${ }^{7}$ reveal that Japanese nuclear output declined by almost $64.7 \%$ from 2010 to 2011, while overall electricity production declined by a little under $6 \%$. Electricity produced from

\footnotetext{
${ }^{7}$ The electricity sector was defined as "main activity producer electric plants" plus "auto-producer electricity plants."
} 
natural gas (supplied almost entirely by LNG imports) and oil products made up for most of the lost nuclear generation. Natural gas consumption by the electricity sector jumped by more than $25.3 \%$ from 2010 to 2011, while consumption of oil products increased by almost $46.7 \%$. Nevertheless, since oil product use was much smaller in 2010 , the energy content of the increased natural gas use was more than double the energy content of the increased oil product use. Somewhat surprisingly, the energy content of coal used to generate electricity fell by almost $5.4 \%$ from 2010 to 2011 . From 2011 to 2012 there was a further, more than $84.3 \%$, decline in nuclear generation accompanied by an additional, almost $1.6 \%$, decline in electricity output. The energy content of natural gas, oil products, and coal used to produce electricity all rose in 2012 relative to 2011 . The increase was more than $21 \%$ for oil products, almost $7.5 \%$ for coal and a little under $5.6 \%$ for natural gas.

The final influence on the LNG spot price that we will consider is the contract price for LNG. If importers can reschedule long-term contract cargoes, they will be encouraged to buy spot when the difference between the contract price and the prevailing spot price exceeds what might be expected in the future. Indexation of contract prices to oil prices, which would mechanically tie oil and contract prices, then would also link the oil price to the spot LNG price.

\section{Related literature}

There is a substantial literature examining the relationship between the spot price of natural gas and the spot prices of other energy commodities, especially oil. Most of these papers focus on the US and UK energy markets. A major reason is that spot markets have determined natural gas prices in those countries for longer than elsewhere in the world. The markets for natural gas delivered at HH or NBP also have very deep derivatives markets associated with them and many more participants than the Japanese and Korean markets for spot LNG imports.

In one of the earliest papers examining the relationship between natural gas and oil prices, Serletis and Herbert (1999) tested (among other things) for common trends in daily $\mathrm{HH}$ prices, the price of electricity in PJM, and the price of residual fuel oil at New York Harbor from October 1996 through November 1997. A follow-up paper by Serletis and Rangel-Ruiz (2002) examined the existence of common price cycles in the daily HH prices and WTI oil from 1991 through 2001.

Since most energy price series have a unit root, and competing fuels are subject to a common set of exogenous shocks, studies that examine the relationship among commodity prices usually test for the existence (or lack thereof) of a cointegrating relationship. Bachmeier and Griffin (2006) found, among other results, that crosscommodity cointegration in the US is weak, and conclude that the market for energy can only be considered a single market for primary energy in the very long run. By contrast, Asche, Osmundsen and Sandsmark (2006) found the prices of crude oil, natural gas, and electricity to be cointegrated in the UK, and concluded that there was a single primary energy market in the UK, with the crude oil price being exogenous. They also concluded, however, that changes in regulatory structures and capacity constraints can alter the extent to which prices appear to be cointegrated. 
Traders had long believed in a historical "rule-of-thumb" ratio of WTI to the Henry Hub of 10:1, so that natural gas per MMBTU priced at one-tenth the price of a barrel of crude oil. Practitioners were also aware that this relationship seemed to disintegrate during the late 1990 s and early 2000 s, evolving to something closer to 6:1. Villar and Joutz (2006) were among the first to systematically examine the apparent decoupling of WTI crude oil and $\mathrm{HH}$ natural gas prices. They documented that a cointegrating relationship between the two prices exhibited a positive time trend, indicating an evolving rather than constant long-run relationship.

Brown and Yücel (2008) used an error correction model (ECM) to analyze weekly prices from January 1994 through July 2006. They found the price series to be cointegrated over this period, indicating a stable long-run relationship. However, they also found that a cointegrating relationship does not exist if they consider the shorter time period of June 1997 through July 2006.

Hartley, Medlock, and Rosthal (2008) examined monthly data from the US for the period February 1990 through October 2006. They demonstrated the existence of a long-run cointegrating relationship over this period between the residual fuel oil price, the natural gas price, and a variable measuring technological change in electricity generation. They claimed that the absence of the latter variable from previous studies could explain why those authors had found the cointegrating relationship between natural gas and oil prices to be unstable.

More recently, Ramberg and Parsons (2012) again found that the cointegrating relationship between natural gas and oil prices was unstable. In particular, they show that while the prices may be tied together, substantial shifts in the underlying relationship can make the confidence interval for the price relationship very large. They nevertheless conclude that even if the long-run pricing relationship changes, a relationship should eventually re-establish as new technologies introduce new margins of substitution between the fuels.

Using monthly data from January 1995 through December 2011, Hartley and Medlock (2014) estimated a cointegrating relationship that included the exchange rate for the US dollar in addition to a variable to capture technological change, as suggested by Hartley, Medlock, and Rosthal (2008). Hartley and Medlock (2014) observed that while the US trades crude oil internationally, natural gas had predominantly remained a non-traded good, at least insofar as the core Texas and Louisiana market is concerned. ${ }^{8}$ The absence of LNG trade connecting the US Gulf Coast and markets in Europe and Asia has prevented spot natural gas prices in North America, Europe, and Asia from reaching an equilibrium reflecting transport costs. With oil being traded internationally, however, and with most of the demand being priced in currencies other than the US dollar, any change in the foreign exchange value of the dollar will alter the price of oil expressed in dollars per barrel.

\footnotetext{
${ }^{8}$ LNG continues to be imported into end-of-pipe markets but these disconnect from the Henry Hub in Louisiana when weather shocks raise demand above existing pipeline capacity and result in basis blowouts.
} 
The paper by Ji, Geng, and Fan (2014) is the only one we could find examining cointegration between Asian natural gas and oil prices. Using European, US and Asian monthly data from January 1997 to August 2011, they examine panel cointegration of natural gas prices not only to oil prices but also to a variable developed by Kilian (2009) to measure global economic activity. They use the Japanese monthly average LNG import price as the dependent variable for Asia. They find that international oil prices and global economic activity both have a significant positive impact on Japanese LNG import prices. Oil prices were found to be more important, and global economic activity less important, in Japan than in the other two regions.

The main difference between our paper and Ji, Geng, and Fan's (2014) is that we are interested in the relationship between spot LNG prices and the price of oil. The Japanese monthly average LNG import price they use is a mixture of spot and contract prices. The latter will be closely related to oil because of the price indexation in contracts. Our period of analysis is also much shorter that theirs, since the JKM price has only been available since February 2009. Like some of the early papers looking at the cointegration of natural gas and oil prices, we also examine daily data. This gives a sample size large enough to apply time series techniques. Most of the later papers used data at the monthly frequency because they wanted to include additional variables in the analysis, and these were only available on a monthly basis.

Another difference between our paper and most of the previous literature is that we include coal prices in the analysis. As we noted in the introduction, coal is the dominant fuel in the Asia Pacific region. Coal is also important in the US, yet few papers have examined the relationship of US natural gas to coal prices. This may be because US coal prices vary so widely across the nation that it is difficult to choose a representative market price similar to $\mathrm{HH}$ for natural gas. We use a spot market price for thermal coal shipped directly to the east Asian region.

\section{Data}

The key variable of interest is the JKM price for spot LNG trades in northeast Asia. The data was obtained from Platts in units of \$US/MMBTU. It covers the period from when the variable was first calculated in February 2, 2009 up to April 30, 2015 (2,279 days). The other variables of interest are spot prices of crude oil, residual fuel oil, and coal. Although some early papers in the literature discussed above used WTI as the oil price, in this study, we use the Brent crude oil price. Crude oil is the most actively traded energy commodity, and crude prices generally are closely related to each other with small differentials reflecting variations in quality. In the period under study, however, there was a persistent deviation in the WTI-Brent spread that indicated WTI was not truly reflective of world oil market conditions. ${ }^{9}$ In addition, Asian LNG contracts are

\footnotetext{
${ }^{9}$ WTI and Brent are of similar quality, but traditionally WTI was priced slightly higher than Brent. After 2008, however, there was a persistent inversion and massive increase in the spread. Büyükşahin et al. (2013) studied this in detail and provided evidence that "the main driver of the Brent-WTI spread patterns in late Fall 2008 and Winter 2009
} 
indexed to the Japan Crude Cocktail (JCC) or Brent. The JCC index, which is the average price of customs-cleared crude oil imports into Japan, is an illiquid product. We therefore used the Brent price for the crude oil spot market price. ${ }^{10}$ We obtained the data from the EIA website in units of $\$$ US/barrel and used the EIA conversion factor of 5.8 MMBTU/barrel to re-express the price in \$US/MMBTU.

Some of the previous papers, including those by Serletis and Herbert (1999) and Hartley, Medlock, and Rosthal (2008), found evidence that the natural gas price in the US was more directly related to the residual fuel oil price than the price of crude oil. ${ }^{11}$ We therefore also included the Singaporean residual fuel oil price (obtained from Platts in $\$ / \mathrm{MMBTU}$ ) as a relevant traded fuel oil price from the Asian region.

As we noted in the previous section, to reflect the prominent role of coal in Asia we also included a coal price. Since Japan, South Korea, China, and Taiwan are all major importers of thermal coal from Australia, we chose the Newcastle (Australia) FOB 6300 $\mathrm{kcal} / \mathrm{kg}$ (thermal) coal price from Platts. Since this is measured in $\$ U S /$ tonne, we used $6300 \mathrm{kcal} / \mathrm{kg}=24.9811 \mathrm{MMBTU} /$ tonne to convert this price to the units used for the other prices, namely $\$$ US/MMBTU.

In common with other studies that use daily prices, we examine the relationship between nominal prices. This is in large part because it is difficult to find a suitable price deflator at a daily frequency. If the various fuels were used only as inputs to electricity generation, a daily wholesale electricity price could be used. ${ }^{12}$ However, none of Japan, South Korea, China, or Taiwan have fully market-determined electricity prices. Even if they all did, it is not clear how they should be weighted to arrive at a suitable daily electricity price index for the region. In addition, these countries use the various energy commodities for more than electricity generation.

were storage constraints and a glut of crude in Cushing amid a sharp drop in energy demand, greater output from the Bakken and Canadian oil fields and transportation bottlenecks." They also found that the WTI-Brent spread was "weakly linked to world macroeconomic fundamentals" as measured by the Kilian (2009) index and that "after controlling for macroeconomic and physical market fundamentals, the WTI-Brent spread is partly predicted by the aggregate long positions of commodity index traders ... in WTI futures."

${ }^{10}$ Scarpa and Manera (2008) suggest using the WTI as a hedging instrument for JCC. In light of the issues discussed in the previous footnote, Brent would be more appropriate than WTI in our sample period.

${ }^{11}$ A report issued in 2012 by the Organisation of the Petroleum Exporting Countries (OPEC 2012) projected that residual fuel oil would be the only fuel to experience a demand decline from 2011 to 2035 . The reason given was that natural gas would displace it from electricity generation. The same OPEC study also estimated that the Asia-Pacific region constituted a third of global residual fuel oil demand.

${ }^{12}$ From the perspective of a cost-minimizing electricity producer, the relevant real input price for each fuel is the nominal price times the heat rate of the generating plant divided by the price of electricity. Hartley, Medlock, and Rosthal (2008) used monthly US industrial electricity retail prices as the price deflator. 
Figure 2 shows that three of the four prices have tended to fluctuate in a similar pattern, with coal remaining much more stable than the other three. The close relationship between the residual fuel price and oil price is particularly evident. This is not surprising, since it is well known that a linear program can reasonably accurately represent the oil refining process. Hence, the prices of the outputs should all be closely related to the price of the main input-crude oil.

Figure 2: The four energy price series

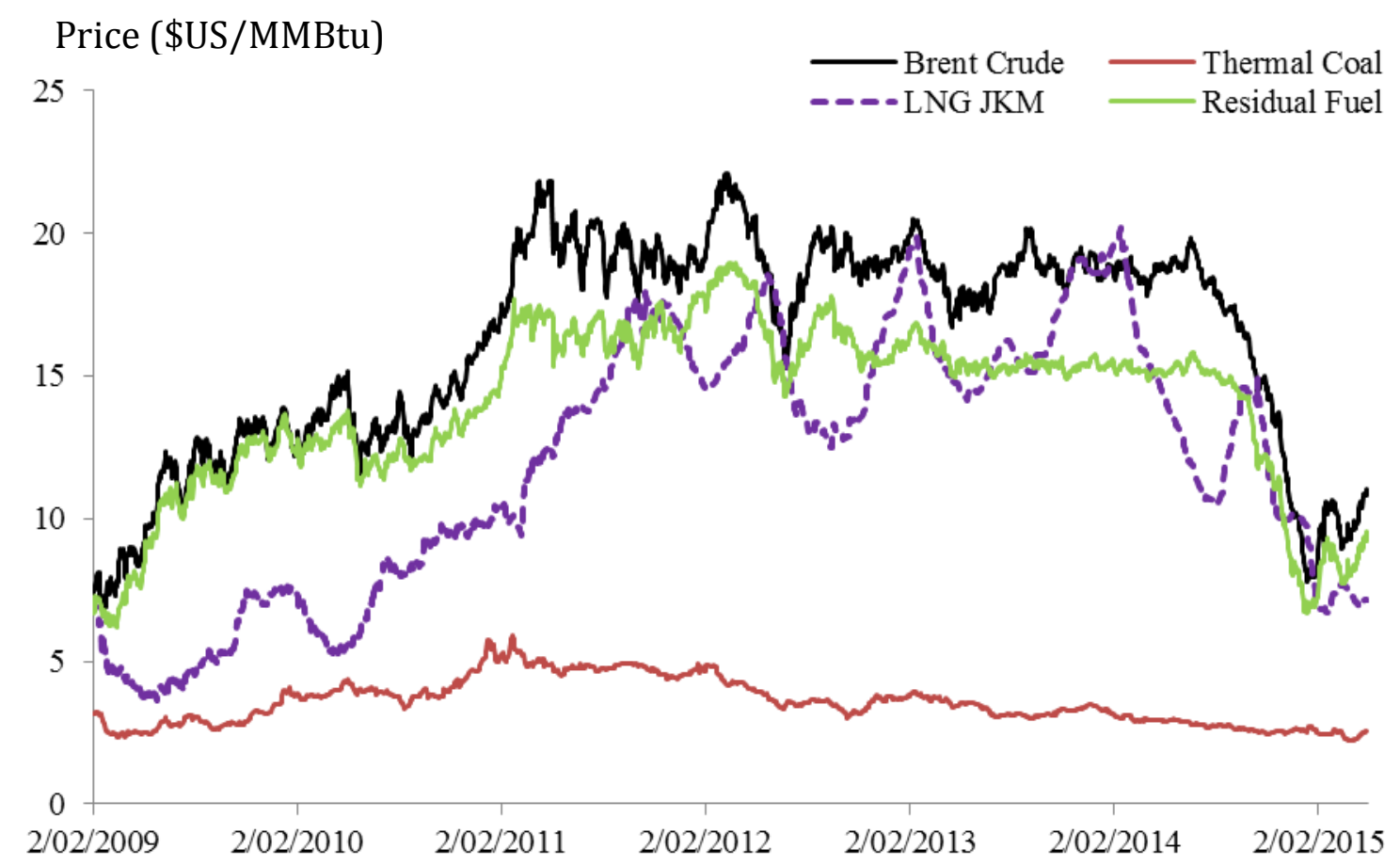

Data sources: Platts and EIA

We will estimate a vector error correction model (VECM) on a vector $Y_{t}$ of the natural logarithms of the fuel prices. We use the natural logarithm transformation for several reasons. First, it makes our results more comparable with previous studies that have also been based on the natural logarithms of the prices. Second, the value used for the energy content conversions of the fuels then becomes irrelevant to the subsequent analysis because different conversion constants would simply change the estimated intercepts. Third, the issue of real versus nominal values becomes less important since the dynamic adjustment equation will effectively be looking at percentage changes in the different fuel prices and the missing inflation variable will be part of the error term.

The VECM estimation procedure requires evenly spaced data in the time domain, while our series have missing observations for weekends and public holidays. We investigated three different methods for interpolating the missing data: linear interpolation, cubic interpolation, and cubic spline interpolation. For each vector, we investigated the eigenvalue stability, residual normality, residual serial correlation, and conditional 
heteroskedasticity of the resulting vector autoregression (VAR). Based on these VAR diagnostic tests, we decided to work with cubic spline interpolation to fill in the missing values. ${ }^{13}$ Hereafter, we use LNG, RFO, coal, and Brent to refer to the natural logarithms of the energy-content adjusted and cubic spline interpolated prices of the fuels.

\section{Analysis and Results}

Before estimating the VECM, we first checked for the degree of integration for each of the four price series using both the augmented Dickey and Fuller (1979) and Phillips and Perron (1988) tests. The results presented in Table 1 suggest that all four series have a unit root, that is, are $I(1)$.

Table 1: Augmented Dickey Fuller (ADF) and Phillips-Perron (PP) unit root tests (pvalues) ${ }^{*}$

\begin{tabular}{|c|cccc|cccc|}
\hline & \multicolumn{4}{|c|}{ ADF } & \multicolumn{3}{c|}{ PP } \\
\hline Lags & LNG & RFO & Coal & Brent & LNG & RFO & Coal & Brent \\
\hline 1 & 0.7980 & 0.0664 & 0.6490 & 0.0962 & 0.8226 & 0.1575 & 0.7744 & 0.1074 \\
2 & 0.8281 & 0.1264 & 0.7730 & 0.1299 & 0.8218 & 0.1592 & 0.7619 & 0.1085 \\
3 & 0.8129 & 0.1762 & 0.7527 & 0.1292 & 0.8222 & 0.1641 & 0.7603 & 0.1097 \\
4 & 0.8001 & 0.1944 & 0.7366 & 0.1423 & 0.8193 & 0.1675 & 0.7565 & 0.1097 \\
5 & 0.7883 & 0.1880 & 0.7442 & 0.1724 & 0.8152 & 0.1698 & 0.7527 & 0.1096 \\
6 & 0.7566 & 0.1605 & 0.7300 & 0.1951 & 0.8101 & 0.1703 & 0.7491 & 0.1095 \\
7 & 0.7383 & 0.1663 & 0.7199 & 0.2038 & 0.8048 & 0.1695 & 0.7452 & 0.1094 \\
\hline
\end{tabular}

* The $\mathrm{p}$-values for the first differenced variables are all less than $10^{-4}$

Next, we used the varsoc command in STATA to compute four lag length selection criteria-the final prediction error (FPE), Akiake's information criterion (AIC), the Hannan-Quinn information criterion (HQIC), and Schwarz's Bayesian information criterion (SBIC) - and a sequence of likelihood ratio (LR) tests. The results, presented in Table 2, are inconsistent. Since it may be prudent to allow for weekly effects (seven lags in daily data), we chose the longest indicated lag length of ten for the VAR. This corresponds to a lag length of nine for the VECM.

\footnotetext{
${ }^{13}$ We emphasize, however, that the different VAR systems that we examined were barely distinguishable.
} 
Table 2: Lag length selection length criteria

\begin{tabular}{|l|cccccccc|}
\hline Lag & LL & LR & df & $\mathrm{p}$ & FPE & AIC & HQIC & SBIC \\
\hline 0 & 4388.04 & & & & $2.4 \mathrm{e}-07$ & -3.87112 & -3.86743 & -3.861 \\
1 & 27087.4 & 45399 & 16 & 0.000 & $4.9 \mathrm{e}-16$ & -23.9005 & -23.8821 & -23.85 \\
2 & 27508.5 & 842.23 & 16 & 0.000 & $3.4 \mathrm{e}-16$ & -24.2583 & -24.225 & -24.1673 \\
3 & 27738.1 & 459.26 & 16 & 0.000 & $2.8 \mathrm{e}-16$ & -24.4469 & -24.3989 & $-24.3154^{*}$ \\
4 & 27776.5 & 76.821 & 16 & 0.000 & $2.8 \mathrm{e}-16$ & -24.4667 & $-24.404^{*}$ & -24.2948 \\
5 & 27796.9 & 40.871 & 16 & 0.001 & $2.8 \mathrm{e}-16$ & -24.4706 & -24.3931 & -24.2583 \\
6 & 27824 & 54.177 & 16 & 0.000 & $2.7 \mathrm{e}-16$ & -24.4804 & -24.3882 & -24.2276 \\
7 & 27851 & 53.995 & 16 & 0.000 & $2.7 \mathrm{e}-16$ & -24.4901 & -24.3831 & -24.1969 \\
8 & 27881.1 & 60.062 & 16 & 0.000 & $2.7 \mathrm{e}-16$ & -24.5025 & -24.3807 & -24.1688 \\
9 & 27895 & 27.859 & 16 & 0.033 & $2.7 \mathrm{e}-16$ & -24.5007 & -24.3642 & -24.1266 \\
10 & 27916.5 & $43.011^{*}$ & 16 & 0.000 & $2.7 \mathrm{e}-16^{*}$ & - & -24.3543 & -24.091 \\
& & & & & & $24.5055^{*}$ & & \\
11 & 27924.2 & 15.316 & 16 & 0.502 & $2.7 \mathrm{e}-16$ & -24.4982 & -24.3321 & -24.0432 \\
12 & 27930.6 & 12.976 & 16 & 0.675 & $2.7 \mathrm{e}-16$ & -24.4898 & -24.309 & -23.9943 \\
13 & 27938.4 & 15.466 & 16 & 0.491 & $2.7 \mathrm{e}-16$ & -24.4825 & -24.2869 & -23.9466 \\
14 & 27951.5 & 26.224 & 16 & 0.051 & $2.7 \mathrm{e}-16$ & -24.4799 & -24.2696 & -23.9036 \\
\hline
\end{tabular}

Table 3 presents the results of the STATA vecrank command (with an unrestricted constant and no trend) used to test for the number of cointegrating relationships. Although the max statistic suggests that there may only be one, the STATA manual notes that the max statistic is less often used than the trace statistic since the former does not take account of the multiple testing problem. We proceed on the basis that there are two cointegrating relationships, but we also examined models with just one. In the latter case, we found that the cointegrating relationship for the LNG price became essentially the same as in the two-equation case discussed below, but the two-equation model also allowed adjustments in the RFO and Brent price to respond to errors in a long-run cointegrating relationship with Brent. Although we are primarily interested in the LNG price, the more complete system also allows all the fuel prices to affect the short-run evolution of the LNG price, as we discuss in more detail below. In the subsequent analysis, we normalized the two cointegrating equations so that the coefficient on LNG was 1 in the first equation and the coefficient on RFO was 1 in the second equation. 
Table 3: Johansen Tests for Cointegration (10 lags)

\begin{tabular}{|c|c|c|c|c|c|c|c|}
\hline $\begin{array}{l}\text { Maximum } \\
\text { rank }\end{array}$ & parameters & LL & eigenvalue & $\begin{array}{l}\text { Trace } \\
\text { statistic }\end{array}$ & $\begin{array}{l}5 \% \\
\text { critical } \\
\text { value }\end{array}$ & $\begin{array}{l}\text { Max } \\
\text { statistic }\end{array}$ & $\begin{array}{l}5 \% \\
\text { critical } \\
\text { value }\end{array}$ \\
\hline 0 & 148 & 27848.905 & & 70.5251 & 47.21 & 37.3236 & 27.07 \\
\hline 1 & 155 & 27867.567 & 0.01631 & 33.2015 & 29.68 & 19.1018 & 20.97 \\
\hline 2 & 160 & 27877.118 & 0.00838 & $14.0997^{*}$ & 15.41 & 10.1381 & 14.07 \\
\hline 3 & 163 & 27882.187 & 0.00446 & 3.9616 & 3.76 & 3.9616 & 3.76 \\
\hline 4 & 164 & 27884.168 & 0.00174 & & & & \\
\hline
\end{tabular}

The VECM was estimated using the two-step procedure in $\mathrm{JMulTi}{ }^{14}$ Initially, we allowed month and day of the week indicator variables to be part of the short-run dynamic adjustment equations in the VECM. The thought was that there might be systematic seasonal or weekly effects on the price movements. However, very few of the individual coefficients were statistically significantly different from zero at even the $10 \%$ level, and in the LNG equation none were at the 5\% level. A test for the weekly effects being zero in all equations yielded $\chi_{24}^{2}=22.53$ with a $p$-value of 0.5478 . In the case of the monthly effects, the corresponding test yielded $\chi_{44}^{2}=46.49$ with a $p$-value of 0.3700. Finally, a test of them all being zero in all equations yielded $\chi_{68}^{2}=69.12$ with a $p$-value of 0.4392 . Hence, we dropped these variables from the subsequent analysis. ${ }^{15}$

From the first set of results in Table 4, we conclude that the coal price can be omitted from both cointegrating equations. The resulting model B is the second set of estimated coefficients in Table 4 . The test statistic for comparing models A and B, namely $\chi_{2}^{2}=1.02$ with a $p$-value of 0.600 , confirms that we cannot reject the hypothesis that the coal coefficients are zero in both equations. This finding was somewhat surprising given the important role of coal as a fuel in the Asia Pacific. While many previous authors also have not found strong interactions between coal, natural gas, and oil prices, this might be the result of not having a good representative coal price variable. Given the importance of Australian exports of coal in the Asia Pacific, we believe that we have a reasonable variable, ${ }^{16}$ but we still find no long-run effect of the coal price on either LNG or fuel oil prices.

\footnotetext{
${ }^{14}$ The results from using maximum likelihood to estimate models A through $\mathrm{C}$ were almost identical.

${ }^{15}$ We also collected data from http://www.degreedays.net/pro/ on heating and cooling degree days for several major cities in Japan, South Korea, and China (and defined "extreme" temperatures in different ways) but again we did not find that their coefficients were statistically significantly different from zero.

${ }^{16}$ China is the dominant coal consumer and producer in the region, however, and its domestic coal prices might not be closely related to the international traded coal price.
} 
Table 4: Comparison of VECM Specifications ( $t$-statistics in parentheses)

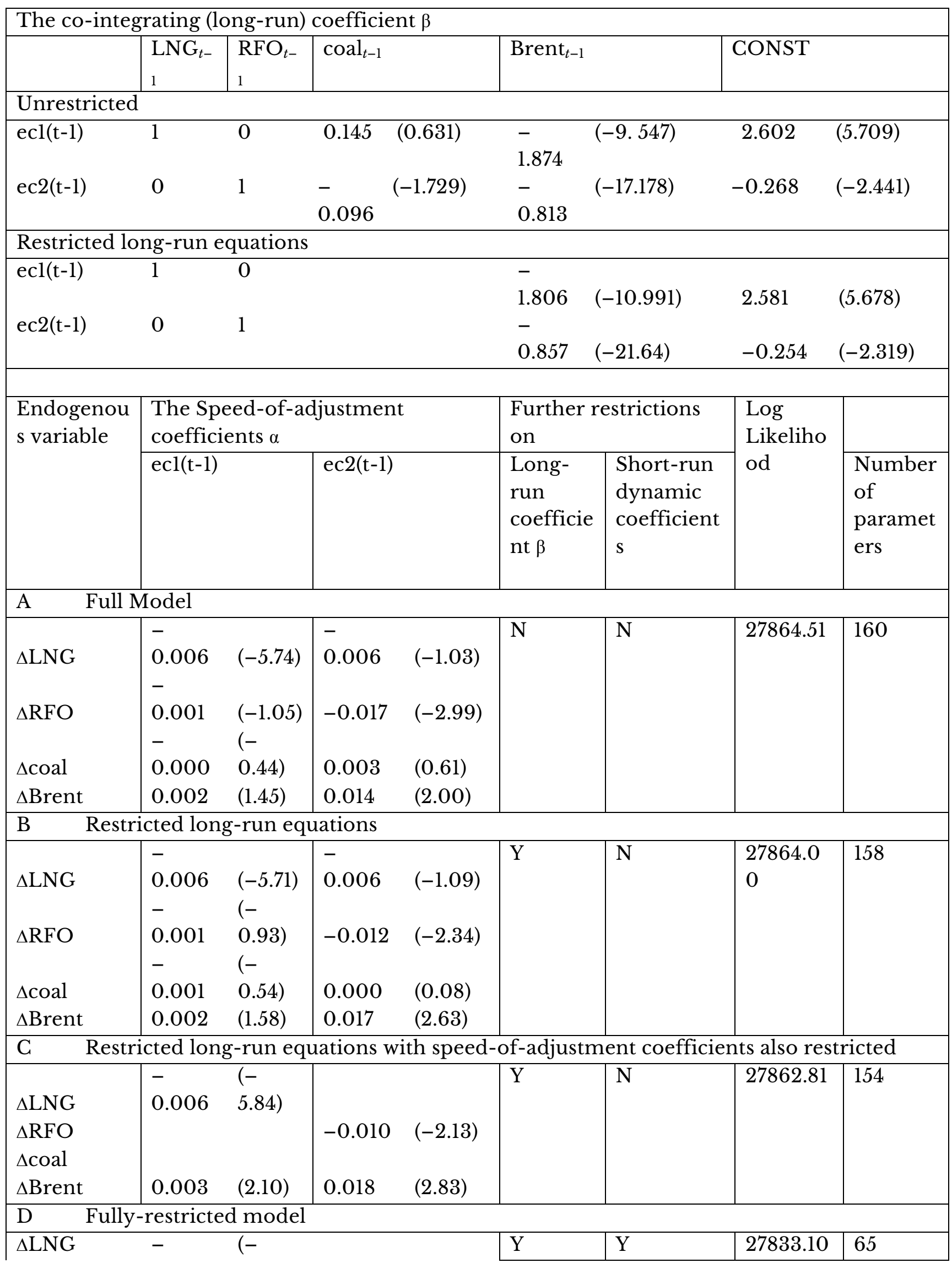




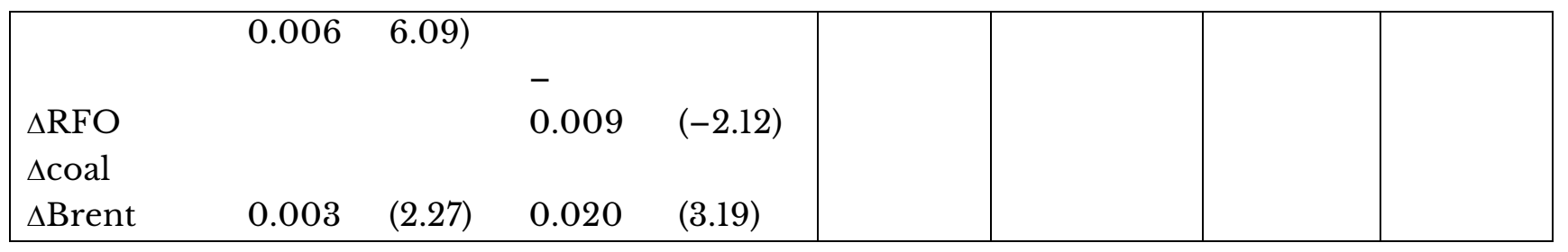

Notes: Ten lags in VAR, nine lags in VECM. In addition to the restrictions in model C, model D restricts coefficients in the short-run dynamics using automatic search in JMulTi.

The cointegrating equation for LNG implies that the long-run elasticity of the LNG price with respect to Brent is around 1.8. The implication is that the LNG price magnifies fluctuations in Brent in the long run. ${ }^{17}$ By contrast, the cointegrating equation for RFO implies that RFO adjusts less than proportionately to changes in Brent in the long run.

The model B estimates suggest that LNG responds only to errors in the LNG cointegrating equation and symmetrically RFO responds only to errors in the RFO cointegrating equation. It also seems that coal does not respond to either cointegrating equation error term. The resulting model estimates from setting these error correction adjustment parameters to zero are listed as model $\mathrm{C}$ in Table 4. The test statistic for comparing model $\mathrm{C}$ with model $\mathrm{B}$ is $\chi_{4}^{2}=2.38$ with a $p$-value of 0.666 . Hence, we do not reject the null hypothesis that the speed-of-adjustment coefficients that are individually insignificantly different from zero in model B are also jointly insignificant.

Since the error correction coefficients for LNG and RFO are negative, and the coefficients for Brent are positive (Brent appears on the right hand side of the cointegrating equations with positive coefficients), the dynamic adjustment process will be stable. The result that Brent also responds to the two error correction terms contrasts with many previous studies that have found oil prices unresponsive to such deviations in the cointegrating relationships. It might perhaps reflect the large role of these Asian countries in the world oil market. The adjustment of Brent in response to deviations from the cointegrating relationship linking Brent and RFO in particular might explain why the long-run elasticity of RFO with respect to Brent is less than 1.

The estimated magnitudes of the reactions of RFO and Brent to a deviation from the RFO cointegrating relationship are much larger than the reactions of LNG and Brent to deviations in the LNG cointegrating relationship. Evidently, forces tending to reestablish the Brent and RFO long-run relationship are stronger than the forces operating on the oil/LNG price differential.

Table 5 presents the short-run dynamic response coefficients in model C. Each fuel price tends to respond most strongly to lagged own-price changes. While changes in

${ }^{17}$ Although Figure 1 shows that the rolling standard deviation of LNG roughly equaled the rolling standard deviation of Brent over 28-day periods, over 56-day periods the mean rolling standard deviation of LNG is about $22 \%$ higher. 
LNG and RFO prices the previous day and week change the current Brent price, lagged Brent prices have a stronger effect on RFO price adjustments than vice versa. The LNG price responds significantly to week-ago changes in the RFO, coal, and Brent prices, and also to the previous day's change in Brent. Finally, the short-run effects of coal on the other fuel prices tend to be weaker and more delayed than the interactions between LNG, RFO, and Brent.

Model D drops the short-run dynamic response coefficients in Table 5 that were individually and jointly not statistically significantly different from zero. The test for the joint significance of the coefficients dropped from model $\mathrm{C}$ yields $\chi_{89}^{2}=59.42$ with a $p$-value of 0.993 .

Table 6 presents the estimates of the remaining short-run dynamic response coefficients. Figure 3 presents the impulse response functions for 28 days from model $\mathrm{D}^{18}$ along with $95 \%$ confidence intervals. These are calculated from the corresponding VAR representation of the estimated VECM model using bootstrap methods.

\footnotetext{
${ }^{18}$ The impulse response functions for model C look quite similar to the ones graphed in Figure 3.
} 
Table 5: Short-run dynamic response coefficient estimates in model C ( $t$-statistics in parentheses)

\begin{tabular}{|c|c|c|c|c|c|c|c|c|}
\hline \multirow[b]{3}{*}{$\Delta \mathrm{LNG}_{t_{-1}}$} & \multicolumn{8}{|c|}{ Endogenous Variable } \\
\hline & \multicolumn{2}{|c|}{$\Delta \mathrm{LNG}$} & \multicolumn{2}{|c|}{$\Delta \mathrm{RFO}$} & \multicolumn{2}{|c|}{$\Delta$ coal } & \multicolumn{2}{|c|}{$\Delta$ Brent } \\
\hline & 0.259 & $(12.35)$ & 0.013 & $(0.67)$ & 0.010 & $(0.55)$ & 0.064 & $(2.66)$ \\
\hline \multirow{2}{*}{$\Delta \mathrm{LNG}_{t-2}$} & - & $(-8.58)$ & 0.026 & $(1.30)$ & -0.023 & $(-1.29)$ & -0.047 & $(-1.88)$ \\
\hline & 0.185 & & & & & & & \\
\hline$\Delta \mathrm{LNG}_{t-3}$ & 0.024 & $(1.09)$ & 0.012 & $(0.58)$ & 0.017 & $(0.91)$ & -0.012 & $(-0.48)$ \\
\hline$\Delta \mathrm{LNG}_{t-4}$ & 0.06 & $(2.91)$ & -0.006 & $(-0.28)$ & 0.002 & $(0.09)$ & -0.015 & $(-0.58)$ \\
\hline$\Delta \mathrm{LNG}_{t-5}$ & $\begin{array}{l}3 \\
0.010\end{array}$ & $(0.45)$ & -0.029 & $(-1.44)$ & 0.008 & $(0.42)$ & 0.008 & $(0.30)$ \\
\hline$\Delta \mathrm{LNG}_{t-6}$ & 0.091 & $(4.21)$ & -0.023 & $(-1.15)$ & -0.020 & $(-1.12)$ & 0.005 & $(0.20)$ \\
\hline$\Delta \mathrm{LNG}_{t-7}$ & 0.006 & $(0.29)$ & 0.039 & $(1.95)$ & 0.090 & $(5.00)$ & -0.060 & $(-2.37)$ \\
\hline$\Delta \mathrm{LNG}_{t-8}$ & 0.075 & (3.48) & -0.008 & $(-0.40)$ & -0.008 & $(-0.43)$ & 0.036 & $(1.43)$ \\
\hline \multirow[b]{2}{*}{$\Delta \mathrm{LNG}_{t-9}$} & - & $(-1.21)$ & 0.003 & $(0.18)$ & -0.009 & $(-0.53)$ & -0.076 & $(-3.13)$ \\
\hline & 0.025 & & & & & & & \\
\hline \multirow{2}{*}{$\Delta \mathrm{RFO}_{t-1}$} & - & $(-1.72)$ & 0.115 & $(5.04)$ & 0.033 & (1.61) & 0.062 & $(2.15)$ \\
\hline & 0.042 & & & & & & & \\
\hline \multirow{2}{*}{$\Delta \mathrm{RFO}_{t-2}$} & - & $(-1.32)$ & -0.323 & $(-14.13)$ & 0.011 & $(0.54)$ & 0.039 & $(1.36)$ \\
\hline & 0.032 & & & & & & & \\
\hline \multirow{2}{*}{$\Delta \mathrm{RFO}_{t-3}$} & - & $(-1.67)$ & -0.132 & $(-5.51)$ & 0.002 & $(0.10)$ & -0.045 & $(-1.49)$ \\
\hline & 0.043 & & & & & & & \\
\hline \multirow{2}{*}{$\Delta \mathrm{RFO}_{t-4}$} & - & $(-0.99)$ & -0.066 & $(-2.74)$ & -0.003 & $(-0.13)$ & 0.002 & $(0.06)$ \\
\hline & 0.026 & & & & & & & \\
\hline \multirow{2}{*}{$\Delta \mathrm{RFO}_{t-5}$} & - & $(-2.73)$ & -0.097 & $(-4.06)$ & 0.013 & $(0.60)$ & 0.019 & $(0.62)$ \\
\hline & 0.071 & & & & & & & \\
\hline \multirow{2}{*}{$\Delta \mathrm{RFO}_{t-6}$} & - & $(-2.20)$ & 0.030 & $(1.25)$ & 0.030 & (1.41) & 0.048 & (1.61) \\
\hline & 0.057 & & & & & & & \\
\hline \multirow{2}{*}{$\Delta \mathrm{RFO}_{t-7}$} & - & $(-1.30)$ & 0.005 & $(0.20)$ & -0.020 & $(-0.96)$ & 0.056 & (1.91) \\
\hline & 0.033 & & & & & & & \\
\hline \multirow{2}{*}{$\Delta \mathrm{RFO}_{t-8}$} & - & $(-0.27)$ & 0.003 & $(0.12)$ & 0.045 & $(2.22)$ & -0.080 & $(-2.81)$ \\
\hline & 0.006 & & & & & & & \\
\hline$\Delta \mathrm{RFO}_{t-9}$ & 0.018 & $(0.81)$ & 0.041 & $(2.03)$ & 0.002 & $(0.14)$ & 0.036 & $(1.40)$ \\
\hline \multirow{2}{*}{$\Delta \operatorname{coal}_{t-1}$} & - & $(-0.50)$ & 0.029 & $(1.24)$ & 0.369 & $(17.42)$ & -0.028 & $(-0.94)$ \\
\hline & 0.013 & & & & & & & \\
\hline$\Delta \operatorname{coal}_{t-2}$ & 0.009 & $(0.34)$ & 0.008 & $(0.33)$ & -0.187 & $(-8.28)$ & 0.040 & $(1.27)$ \\
\hline \multirow{2}{*}{$\Delta \operatorname{coal}_{t-3}$} & - & $(-0.24)$ & -0.009 & $(-0.35)$ & 0.022 & $(0.95)$ & -0.015 & $(-0.47)$ \\
\hline & 0.007 & & & & & & & \\
\hline$\Delta \mathrm{coal}_{t-4}$ & 0.010 & $(0.36)$ & 0.022 & $(0.86)$ & 0.031 & $(1.34)$ & 0.010 & $(0.31)$ \\
\hline \multirow{2}{*}{$\Delta \operatorname{coal}_{t-5}$} & 0.06 & $(2.52)$ & 0.007 & $(0.29)$ & -0.013 & $(-0.59)$ & 0.045 & $(1.43)$ \\
\hline & 9 & & & & & & & \\
\hline \multirow{2}{*}{$\Delta \operatorname{coal}_{t-6}$} & - & $(-0.30)$ & 0.040 & $(1.60)$ & 0.018 & $(0.81)$ & 0.000 & $(0.01)$ \\
\hline & 0.008 & & & & & & & \\
\hline \multirow{2}{*}{$\Delta \mathrm{coal}_{t-7}$} & - & $(-0.94)$ & -0.042 & $(-1.65)$ & 0.004 & $(0.19)$ & -0.041 & $(-1.29)$ \\
\hline & 0.026 & & & & & & & \\
\hline$\Delta \operatorname{coal}_{t-8}$ & 0.045 & $(1.66)$ & -0.017 & $(-0.67)$ & 0.001 & $(0.02)$ & -0.051 & $(-1.62)$ \\
\hline$\Delta \operatorname{coal}_{t-9}$ & - & $(-1.16)$ & 0.043 & $(1.85)$ & 0.015 & $(0.69)$ & 0.065 & $(2.23)$ \\
\hline
\end{tabular}




\begin{tabular}{|lllllllll|}
\multicolumn{7}{|c|}{0.029} & \multicolumn{7}{c|}{$\mathbf{0 . 2 6 5}$} & $\mathbf{( 1 1 . 5 1 )}$ \\
$\Delta$ Brent $_{t-1}$ & $\mathbf{0 . 0 4}$ & $\mathbf{( 2 . 2 3 )}$ & $\mathbf{0 . 3 7 2}$ & $\mathbf{( 2 0 . 6 2 )}$ & -0.019 & $(-1.19)$ & $\mathbf{0 . 2 6 5}$ \\
$\Delta$ Brent $_{t-2}$ & 0.027 & $(1.29)$ & $\mathbf{0 . 0 5 1}$ & $\mathbf{( 2 . 6 1 )}$ & 0.007 & $(0.39)$ & $\mathbf{- 0 . 2 3 8}$ & $\mathbf{( - 9 . 5 2 )}$ \\
$\Delta$ Brent $_{t-3}$ & 0.034 & $(1.57)$ & $\mathbf{0 . 1 7 2}$ & $\mathbf{( 8 . 5 1 )}$ & 0.007 & $(0.41)$ & 0.04 .2 & $(1.64)$ \\
$\Delta$ Brent $_{t-4}$ & 0.015 & $(0.67)$ & $\mathbf{0 . 0 8 5}$ & $\mathbf{( 4 . 1 3 )}$ & 0.002 & $(0.09)$ & 0.047 & $(1.81)$ \\
$\Delta$ Brent $_{t-5}$ & 0.043 & $(-1.93)$ & $\mathbf{0 . 0 6 9}$ & $\mathbf{( 3 . 3 4 )}$ & -0.000 & $(-0.02)$ & -0.042 & $(-1.63)$ \\
$\Delta$ Brent $_{t-6}$ & $\mathbf{0 . 1 0 6}$ & $\mathbf{( 4 . 7 1 )}$ & 0.019 & $(0.92)$ & -0.030 & $(-1.59)$ & 0.026 & $(1.00)$ \\
$\Delta$ Brent $_{t-7}$ & 0.028 & $(1.24)$ & $\mathbf{0 . 0 5 1}$ & $\mathbf{( 2 . 4 6 )}$ & 0.034 & $(1.81)$ & -0.026 & $(-0.99)$ \\
$\Delta$ Brent $_{t-8}$ & 0.010 & $(0.47)$ & -0.012 & $(-0.59)$ & $\mathbf{- 0 . 0 4 7}$ & $\mathbf{( - 2 . 6 5 )}$ & -0.020 & $(-0.79)$ \\
$\Delta$ Brent $_{t-9}$ & - & $(-0.41)$ & 0.020 & $(1.01)$ & -0.011 & $(-0.61)$ & $\mathbf{0 . 0 6 6}$ & $\mathbf{( 2 . 6 6 )}$ \\
& 0.009 & & & & & & & \\
\hline
\end{tabular}

Focusing first on the leading diagonal of graphs in Figure 3, we see that an own shock to any one of the fuel prices tends to dissipate very slowly. Evidently, the coefficients on the error correction terms are so small that it takes a long time before a shock to any one price is brought back into line with the long-run relationships. In the case of LNG, the effect of the shock oscillates between 1 and 1.2 before reaching a maximum effect of about 1.3 after a week, after which it declines gradually back to about 1.2 after 28 days. For RFO, the effect is almost down to 0.6 after a few days, but then rises gradually to be around 0.8 after 28 days. The effect of a coal price shock on subsequent coal prices settles down to about 1.3 after a few days and stays there for the full 28 -day period. Finally, a unit shock to Brent results in a brief excursion of the price above 1.2, before it settles around 1.1 for about two weeks, and then declines gradually to around 0.9 after 28 days. 